blood is higher in some of the observations than what appears to exist under ordinary circumstances. This arises from the effect of the anxsthetic. If the blood be withdrawn whilst the animal is under the influence of the anæsthetic, upwards of two parts per 1000 may be found, and the results included in the list show that even after the lapse of an hour and a half or two hours the sugar may not have fallen to its standard amount.

\section{UNUSUAL OCCURRENCE IN THE ATTEMPT TO REDUCE $\Lambda$ DISLOCATED HUMERUS.}

\section{By THOMAS SMITH, F.R.C.S.,} SURGEON TO ST. BARTHOLOMEW'S HOSPITAL.

THE following is an account of a case where, in an attempt to reduce a dislocated humerus by manual extension, the anterior integumental fold of the axilla was torn, and the pectoral muscles were ruptured. I am anxious to place the case on record as showing that the above-mentioned catastrophe can take plise without the employment of pulleys, and that its occurrence is no pro of that undue force has been employed in the attempt to reduce a disiocation.

My previous experience would have led me to believe that it was impossible to produce so dire a result with the means used, yet I am now convinced that in this particular case the upper extremity would have been completely torn from the trunk had the extending force been continued for a few seconds beyond the time when it was abruptly arrested.

The gentleman who made the extension was my then house-surgeon, not an athlete, nor was he supposed to possess any extraordinary physical force. He was of medium stature compact and well knit in his frame, and he had not, I should say, put out his full strength, as he was making sustained extension, and I had not asked him to make his final effor when the accident orcurred. The hollow of his foot seemed to pass through the enterior fold of the axilla, as if the latter were formed of wet paper. To an observer it was as if the foot cut its way throum the tissues, and not as if these were torn by excessive stretching. There was nothing about the patient to make one suspect extreme degeneracy of tissue, though his occupation (that of a cellarman) was of an unfavourable kind. On other occasions I have employed far greater force without mischief to patients whose appearance was much more characteristic of degeneracy. Had the catastrophe occurred under the use of the pulleys, I should not have been held blameless, for no mere assertion as to the moderation of the forve employed would have had much weight in face of the effect produced.

J. E-, aged fifty-eight, a cellarman, was admitted under Mr. Thomas Smith's care, April 30th, 1877. Eight weeks before admission he fell on his elbow, his hands being in his pockets at the time. As the result of this accident he suffered from paralysis of the radial nerve, and his arm lost its ordinary mobility, for which he was treated in various ways. On examination at the time of his admission he was found to have suffered a subcoracoid dislocation of the left humerus, which had escaped notice. On May 3rd, with the concurrence of the surgical staff of the hospital, he was put under the influence of ether, and after Mr. Smith had manipulated the limb so as to break down recent adhesions, an attempt was made to reduce the dislocation. The housesurgeon, sitting on the ground by the side of the patient, placed his left foot, covered only by a thin sock, in the axilla ; a jack-towel was fastened by a clove hitch round the arm just above the elbow, the other end of the towel being passed behind the house-surgeon's shoulder, who also made extension by pulling from the patient's wrist. No other force was employed, and no assistance was given by bystanders. After extension had been maintained for a minute or so, the whole of the anterior fold of the axilla, integuments and muscles gave way like " rotten leather." The cavity of the axilla was laid widely open, and pretty free hæemorrhage took place. This was at once arrested by pressure, the patient was lifted on to the operating table, the bleeding vessels were secured, the axilla was washed out with carbolic solution, the wound was partially closed, and drainage established by lint soaked in carbolic lotion.

The pectoral muscles were found to have been almost completely torn, and the large vessels and nerves, with the head of the humerus, were laid bare, but not torn; the dislocation was reduced with ease. No immediate constitutional disturbance followed the accident. The patient took his food well, and his temperature was normal for four days; but as the discharge set in, his strength began to fail, and he died on the ninth day from exhaustion.

On post-mortem examination, diffuse suppuration was found to exist in and around the axilla, and the parts about the upper and middle lobes of the right lung were in a state of consolidation. The heart was flabby; the liver large, pallid, and fatty; the kidneys normal; the spleen large, soft, and semi-fluid; vessels of the size of the tibials were rigid from calcareous degeneration. The muscles generally were paler, softer, and more flabby than normal. At the seat of injury nothing could be ascertained as to their condition as regards degeneracy owing to the amount of sloughing that had taken place. No microscopical examination was made.

\section{ON A PECULIAR FORM OF ALBUMEN IN URINE.}

BY W. R. GOWERS, M.D.,

ASSISTANT PROFESSOR OF CLINICAL MEDICINE IN UNIVERSITY COLLEGE.

THE specimen of urine which presented the following reactions was passed by a patient, beyond middle age, who had previously suffered from glycosuria. Unfortunately no further particulars of the case are to be obtained.

The urine had a specific gravity of 1015, was acid in reaction, pale in colour, clear, and contained no sugar. Heat rendered it opaque from a considerable flocculent precipitate, but when boiled almost the whole of the precipitate disappeared, the urine becoming almost as clear as before the heat was applied. On being slowly heated by a waterbath, it was found that the coagulation occurred at $122^{\circ} \mathrm{F}$., and the precipitate began to disappear a few degrees below the boiling point. When thus slowly heated, the clearing on boiling, although great, was not so complete as when more quickly heated. The precipitate produced by a moderate heat, separated, and boiled with distilled water, dissolved at once.

Nitric acid in moderate quantity, in the cold, produced an abundant precipitate. Nitric acid and heat gave no precipitate: e.g., if the upper part of the urine in a test-tube was boiled, the opacity first produced cleared from the part boiled, a layer of thick opacity remaining at the lower part of the heated part, where the heat applied was less. Nitric acid then dropped through caused no precipitate in the upper heated portion, but an abundant precipitate in the lower, cool part. A larger quantity of nitric acid (equal in bulk to the urine) dissolved all the precipitate thrown down in the cold by a smaller quantity of acid.

With a small quantity of nitric or acetic acid, a compound was formed freely soluble in water, cold or hot: e. g., the copious precipitate produced by several drops of nitric acid in the cold was separated, and washed with distilled water. The first washing contained no trace of albumen (tested by placing it in contact with nitric acid). The second washing gave an abundant precipitate, tested in the same way, but none with heat alone, or with heat and more nitric acid. On adding to the urine a few drops of dilute acetic acid, no precipitate occurred, and none could be produced by heat. The addition of some nitric acid still caused a precipitate.

On rendering the urine slightly alkaline with liquor potassæ, heat produced no precipitate, nor did nitric acid added after heating. Nitric acid alone, in the cold, gave, of course, the same precipitate as before.

Alcohol, in moderate quantity, caused no precipitate. Creasote gave the same amount of precipitate as moderate heat.

The quantity of albumen was found, by Dr. W. Roberts's method, to be $\cdot 858$ grain per ounce. Possibly the data for that method are not quite accurate for an albuminous body different from the ordinary albumen.

The albuminous body shown by these reactions thus differ from tine serum-albumen which commonly occurs in 